\title{
Negative ion multiple-stage mass spectrometric analysis of complex oligosaccharides (everninomicins) in a quadrupole ion trap: implications for charge-remote fragmentation
}

\author{
A. K. Ganguly*a, Guodong Chen ${ }^{\mathrm{b}}$, Birendra N. Pramanik*b, Ibrahim Daaro ${ }^{\mathrm{b}}$, Emily Luk ${ }^{\mathrm{b}}$, \\ Peter L. Bartner ${ }^{\mathrm{b}}$, Anil K. Saksena ${ }^{\mathrm{b}}$, and Viyyoor M. Girijavallabhan ${ }^{\mathrm{b}}$ \\ ${ }^{a}$ Department of Chemistry and Chemical Biology, Stevens Institute of Technology, Hoboken, NJ \\ 07030, USA \\ ${ }^{b}$ Schering-Plough Research Institute, 2015 Galloping Hill Road, Kenilworth, NJ 07033, USA \\ E-mail:AKGANGULY1@aol.com
}

This paper is dedicated to Dr. Sukh Dev on the happy occasion of his $80^{\text {th }}$ birthday and for his brilliant contributions in the area of synthesis of natural products.

(received 28 Oct 02; accepted 20 Jan 03; published on the web 28 Jan 03)

\begin{abstract}
Negative ion electrospray ionization (ESI) tandem mass spectrometry (MS/MS) by a quadrupole ion-trap has been utilized to characterize a class of complex oligosaccharide antibiotics (everninomicins), that includes everninomicin-D, SCH 27899, amino everninomicin (SCH 27900), and SCH 49088 containing a hydroxylamino-ether sugar. The deprotonated molecules are dominant ions in the negative ion ESI mass spectra of these compounds. The multiple-stage mass spectrometric analysis $\left(\mathrm{MS}^{\mathrm{n}}\right)$ of these deprotonated species indicates that the negative charge resides in the deprotonated dichlorophenoxyl group in the substituted aromatic ester ring (ring 1 ) and the fragmentation occurs remote to this charge site in generating simple sugar sequence-specific fragment ions. One exception to this process is SCH 49088 in which the side chain of the hydroxylamino-ether sugar dominates fragmentation pathway in a charge-driven mechanism and results in less structural information.
\end{abstract}

Keywords: Oligosaccharide, everninomicin, ESI-MS ${ }^{\mathrm{n}}$, ion-trap, charge-remote fragmentation

\section{Introduction}

Everninomicins are an important group of oligosaccharide antibiotics produced by Micromonospora carbonacea ${ }^{1}$, that are highly active against gram-positive bacteria such as methicillin-resistant Staphylococcus aureus and vancomycin-resistant enterococci ${ }^{2-4}$. The characteristic structural features of this class of compounds include an eight-sugar backbone with two ortho ester functionalities, a modified nitrosugar, and a completely substituted aromatic ester containing two chlorine atoms. 
Although the early structural characterization work on this class of compounds was based on Ganguly-Sarre chemical degradation procedure, ${ }^{5-7}$ fast-atom bombardment (FAB) mass spectrometry (MS) has become a primary method of characterizing everninomicins ${ }^{8-14}$. However, there are some limitations to this approach, including the limited tandem mass spectrometry (MS/MS) capability for fragmentation pathway studies on sector-based FAB-MS.

Recently, we applied the negative ion FAB-MS and electrospray ionization (ESI) MS for the characterization of everninomicins. ${ }^{15}$ The negative ion FAB-MS provided step-wise fragmentation occurring at sugar ether which was most effective in generating structural information. Although negative ion ESI-MS exhibited limited fragmentation for spectral interpretation, it does have advantages in interfacing high performance liquid chromatography (HPLC). For example, we employed a high resolution ESI HPLC/MS to identify several new Ziracin (SCH 27899) related compounds produced during fermentation and degradation process. ${ }^{16}$ Ziracin is a member of everninomicin class of antibiotics. These results clearly demonstrated the feasibility of using negative ion ESI-MS to analyze everninomicins. Although no detailed MS/MS studies were carried out to elucidate the negative ion fragmentation mechanism, coupling ESI with a tandem mass spectrometer should allow one to perform step-bystep MS/MS experiments in obtaining structural information and fragmentation mechanisms. ${ }^{17}$ The recent developments of the quadrupole ion-trap ${ }^{18-20}$ have enabled fragmentation pathways of complex ions to be studied by multiple-stage mass spectrometric analysis ( $\mathrm{MS}^{\mathrm{n}}$ ) through sequential collision-induced dissociation (CID) ${ }^{21-25}$ In a recent paper, we focused on structural characterization of everninomicins by positive ion ESI-MS ${ }^{\mathrm{n}}$ analysis that demonstrated the usefulness of this technique. ${ }^{26}$ The data suggested in general that a charge-remote fragmentation ${ }^{27-30}$ mechanism predominated for sodiated molecules. ${ }^{26}$ The sodium cation was found to reside in a central location of the sugar chain and fragmentation occurred to trim the end of the molecule.

In this report, we explore the use of negative ion ESI-MS ${ }^{\mathrm{n}}$ in a quadrupole ion-trap mass spectrometer for structural characterization of several members of everninomicins that include everninomicin-D (Scheme 1), ${ }^{2}$ SCH 27899 (Scheme 2), hydrolyzed SCH 27899 (Scheme 3), amino everninomicin (SCH 27900, Scheme 4) ${ }^{31}$ and SCH 49088 containing a hydroxylaminoether sugar (Scheme 5$)^{32}$. The objective of this study is to establish detailed negative ion fragmentation patterns for these compounds by ESI-MS ${ }^{\mathrm{n}}$ including locating the position of the negative charge in the molecule. The implications for charge-remote fragmentation are also discussed.

\section{Results and Discussion}

\section{Everninomicin-D}

The negative ion ESI-MS of everninomicin-D ${ }^{2}$ generated an abundant molecular ion at $\mathrm{m} / \mathrm{z} 1534$ with limited fragment ions at $m / z$ 694, 647 (data not shown). This ESI-MS spectrum did not 
provide adequate structural information of the molecule. The detailed fragmentation information on the deprotonated molecule was obtained by ESI-MS ${ }^{\mathrm{n}}$ studies in the ion-trap.

Figure 1 illustrates a three-stage mass analysis from the deprotonated everninomicin-D molecule $[\mathrm{M}-\mathrm{H}]^{-}$at $m / z 1534$. As expected, the dominant fragment ion is at $m / z 1487$, which is a result of the neutral loss of $\mathrm{HNO}_{2}$ from ring $\mathrm{K}$ (Figure 1A). The further fragmentation of the ion at $\mathrm{m} / \mathrm{z} 1487$ leads to the product ion at $\mathrm{m} / \mathrm{z}$ 647, which defines the left portion of the molecule from the central ortho ester group (C) (Figure 1B). Other high mass product ions at $\mathrm{m} / \mathrm{z} 1443$ and 1375 correspond to neutral losses of $\mathrm{C}_{2} \mathrm{H}_{4} \mathrm{O}$ and $\mathrm{CH}_{3}-\mathrm{CH}=\mathrm{C}\left(\mathrm{OCH}_{3}\right)-\mathrm{C}\left(\mathrm{CH}_{3}\right)=\mathrm{CH}_{2}$ (ring $\mathrm{K}$ cleavage product) from $m / z$ 1487, respectively. The ion at $m / z 647$ further fragments to generate sugar sequence-specific product ions at $m / z 501$ (representing ring 1 , A, and $\mathrm{K}$ ), 489 (containing ring $1, A$, and $B$ ) and 343 (representing ring 1 and $A$ ) (Figure $1 \mathrm{C}$ ). The loss of $\mathrm{CO}_{2}$ from $\mathrm{m} / \mathrm{z} 343$ is likely to produce $\mathrm{m} / \mathrm{z} 299$. The fragment ion at $\mathrm{m} / \mathrm{z} 231$ suggests the negative charge to be located at ring 1 . The fragmentation data are summarized in Scheme 1. Clearly, the negative ion ESI-MS $^{\mathrm{n}}$ of everninomicin-D yields sugar sequence-specific fragment ions with cleavages of sugar ether linkages from right portion of the molecule to the left portion, i.e. $\mathrm{m} / \mathrm{z} 1123$, 951, $933,838,694,548$, and 231 . The deprotonation site is established to be at the acidic -OH group of the aromatic ring 1 with the negative charge remaining immobile during the low energy collisional activations. Since the negative charge is likely "fixed", it is further postulated that fragmentations occur remote to this charge, resulting in sequential cleavage along the sugar backbone from right side of the molecule to the left side.

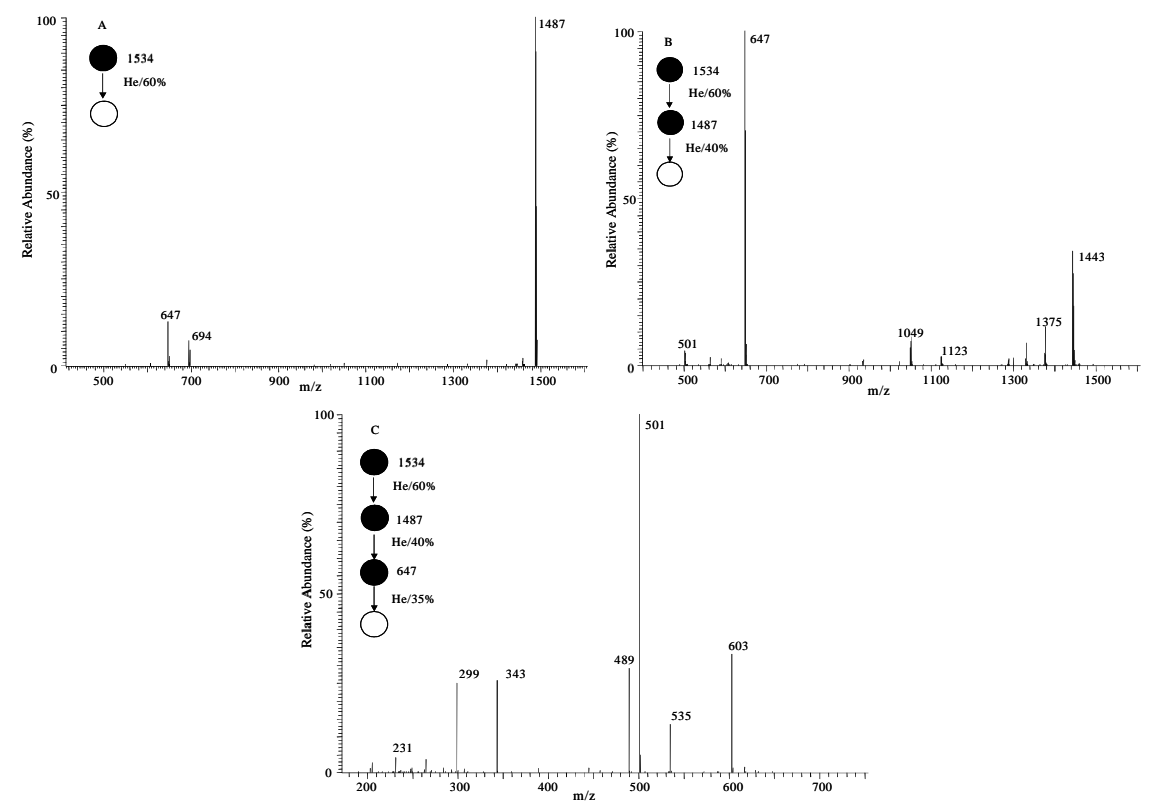

Figure 1. A. The negative product-ion spectrum of ion at $\mathrm{m} / \mathrm{z} 1534\left([\mathrm{M}-\mathrm{H}]^{-}\right)$from everninomicin-D. B. The negative product-ion spectrum $\left(\mathrm{MS}^{3}\right)$ of ion at $\mathrm{m} / \mathrm{z} 1487$ derived from ion at $\mathrm{m} / \mathrm{z}$ 1534. C. The negative product-ion spectrum $\left(\mathrm{MS}^{4}\right)$ of ion at $\mathrm{m} / \mathrm{z} 647$ derived from ion at $m / z 1487$. 


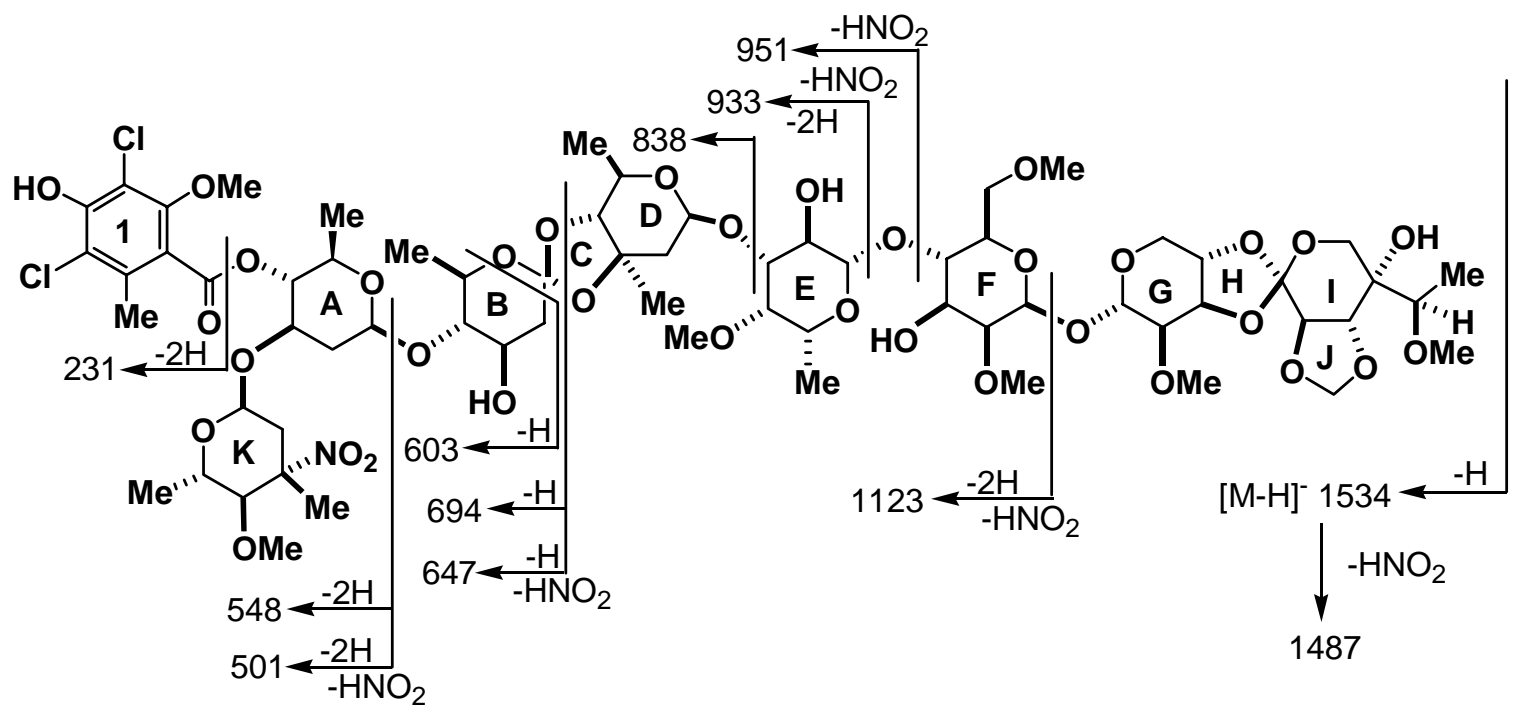

Scheme 1. Proposed negative ion fragmentation pattern of deprotonated everninomicin-D molecule.
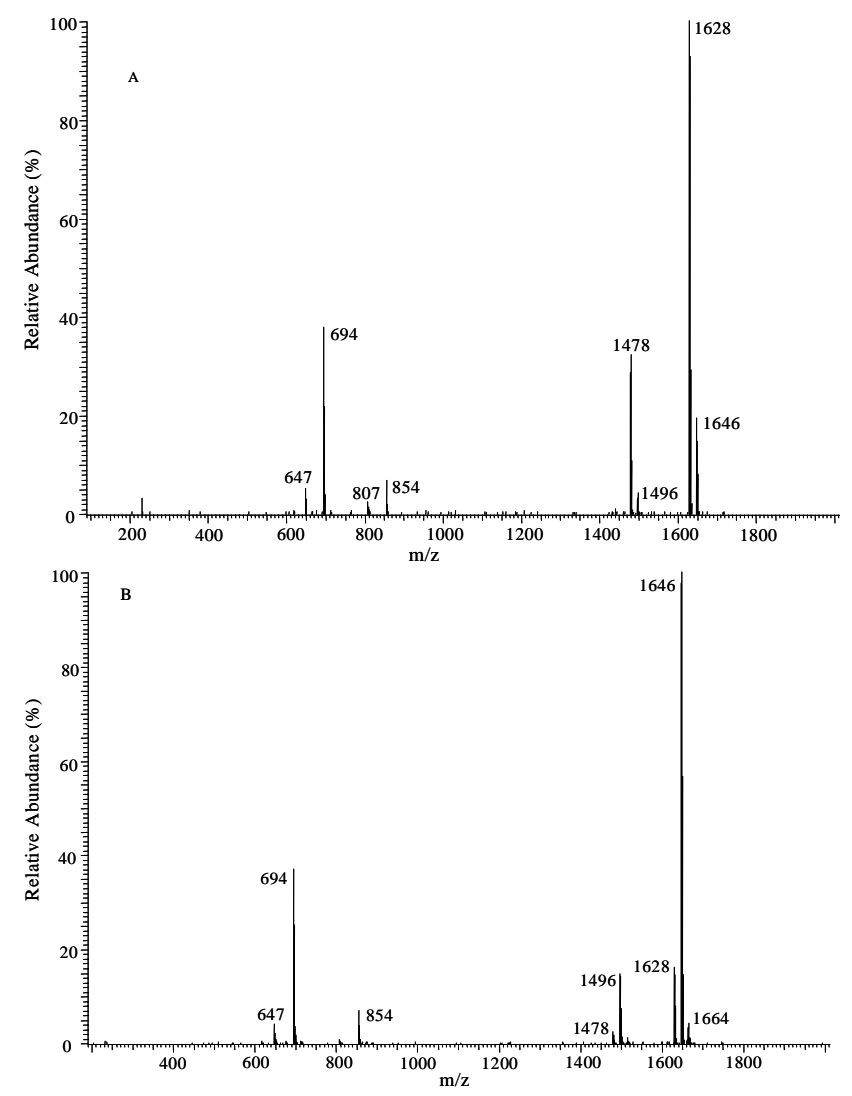

Figure 2. A. The negative ion ESI mass spectrum of SCH 27899 dissolved in acetonitrile. B. The negative ion ESI mass spectrum of SCH 27899 dissolved in a mixture of water and acetonitrile with $0.1 \%$ acetic acid. 


\section{SCH 27899}

SCH 27899 (Ziracin) is a leading drug candidate in the family of everninomicins. The previous work on positive ion ESI studies on SCH 27899 and other everninomicins indicated that the hydrolysis product ions were prominent in the presence of water and acetic acid. ${ }^{26}$ Figure 2 shows negative ion ESI mass spectra of SCH 27899 dissolved in both acetonitrile (Figure 2A) and a mixture of water and acetonitrile with $0.1 \%$ acetic acid (Figure 2B). The base peak in Figure 2A is the deprotonated molecule $[\mathrm{M}-\mathrm{H}]^{-}$at $\mathrm{m} / \mathrm{z} 1628$, whereas the base peak in Figure $2 \mathrm{~B}$ is the deprotonated hydrolysis product $\left[\mathrm{M}+\mathrm{H}_{2} \mathrm{O}-\mathrm{H}\right]^{-}$at $\mathrm{m} / \mathrm{z} 1646$. The structure of SCH 27899 hydrolysis product is illustrated in Scheme 3. It is well documented in the literature that SCH 27899 can undergo sequential hydrolysis at both ortho ester groups with the initial hydrolysis occurring at the central ortho ester group. ${ }^{11}$ The presence of molecular ions as well as hydrolysis product ions has complicated the ESI mass spectra for data interpretation. The most effective way of deriving structural information from fragmentation is to perform tandem mass spectrometric experiments in a multiple-stage fashion.
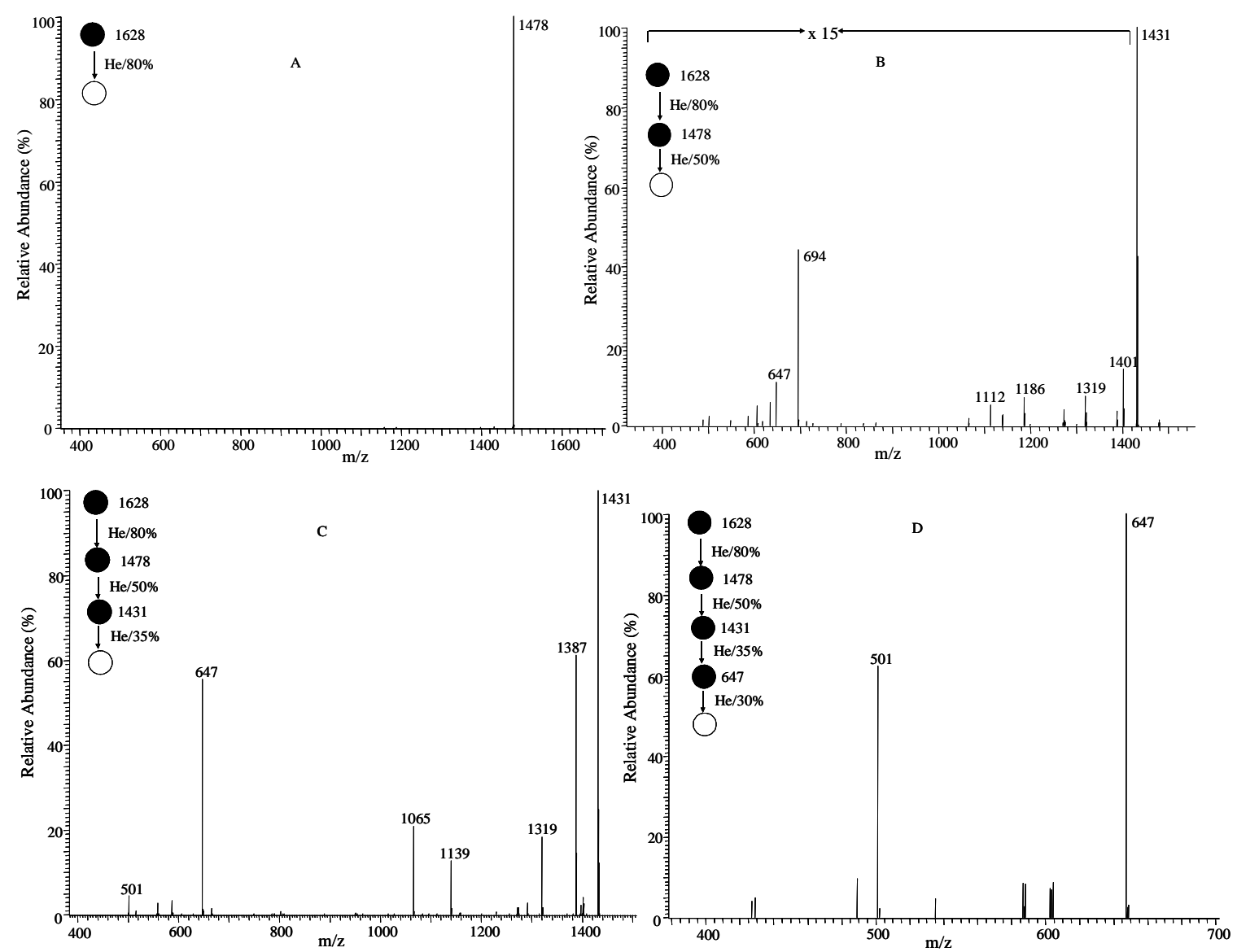

Figure 3. A. The negative product-ion spectrum of ion at $m / z 1628\left([\mathrm{M}-\mathrm{H}]^{-}\right)$from SCH 27899. B. The negative product-ion spectrum $\left(\mathrm{MS}^{3}\right)$ of ion at $\mathrm{m} / \mathrm{z} 1478$ derived from ion at $\mathrm{m} / \mathrm{z} 1628$. C. 
The negative product-ion spectrum $\left(\mathrm{MS}^{4}\right.$ ) of ion at $\mathrm{m} / \mathrm{z} 1431$ derived from ion at $\mathrm{m} / \mathrm{z} 1478$. D. The negative product-ion spectrum $\left(\mathrm{MS}^{5}\right)$ of ion at $\mathrm{m} / \mathrm{z} 647$ derived from ion at $\mathrm{m} / \mathrm{z} 1431$.

Negative ion ESI-MS ${ }^{\mathrm{n}}$ analysis was carried out on the deprotonated SCH 27899 molecule [M - $\mathrm{H}]^{-}$at $m / z$ 1628, as shown in Figure 3. The four-stage mass analysis indicates the following fragmentation pathway: $\mathrm{m} / \mathrm{z} 1628 \rightarrow \mathrm{m} / \mathrm{z} 1478 \rightarrow \mathrm{m} / \mathrm{z} 1431 \rightarrow \mathrm{m} / \mathrm{z} 647 \rightarrow$. This corresponds to the initial neutral loss of the aromatic ring 2 to form the product ion at $\mathrm{m} / \mathrm{z} 1478$ (Figure 3A). A further loss of $\mathrm{HNO}_{2}$ from the nitro-sugar ring $\mathrm{K}$ results in product ions at $\mathrm{m} / \mathrm{z} 1431$ (Figure 3B). Several other product ions at $\mathrm{m} / \mathrm{z}$ 1401, 1387, and 1319 are likely resulted from neutral losses of $\mathrm{CH}_{2} \mathrm{O}, \mathrm{C}_{2} \mathrm{H}_{4} \mathrm{O}$, and $\mathrm{CH}_{3}-\mathrm{CH}=\mathrm{C}\left(\mathrm{OCH}_{3}\right)-\mathrm{C}\left(\mathrm{CH}_{3}\right)=\mathrm{CH}_{2}$ (internal cleavage of ring $\mathrm{K}$ ), respectively. A dominant product ion in the product-ion spectrum of the ion at $\mathrm{m} / \mathrm{z} 1431$ is at $\mathrm{m} / \mathrm{z} 647$, which defines the left portion of the molecule from the central ortho ester group with the loss of $\mathrm{HNO}_{2}$ moiety (Figure 3C). The product ion spectrum of $\mathrm{m} / \mathrm{z} 647$ provides further cleavage of the sugar ether linkage between ring $A$ and $B$ (ions at $m / z 501$ ) (Figure 3D). The sugar sequences in this molecule are also defined by other ions, such as $m / z 1186,1139,951,854,807$, and 548 . Scheme 2 summarizes fragmentation patterns derived from $\mathrm{MS}^{\mathrm{n}}$ studies.

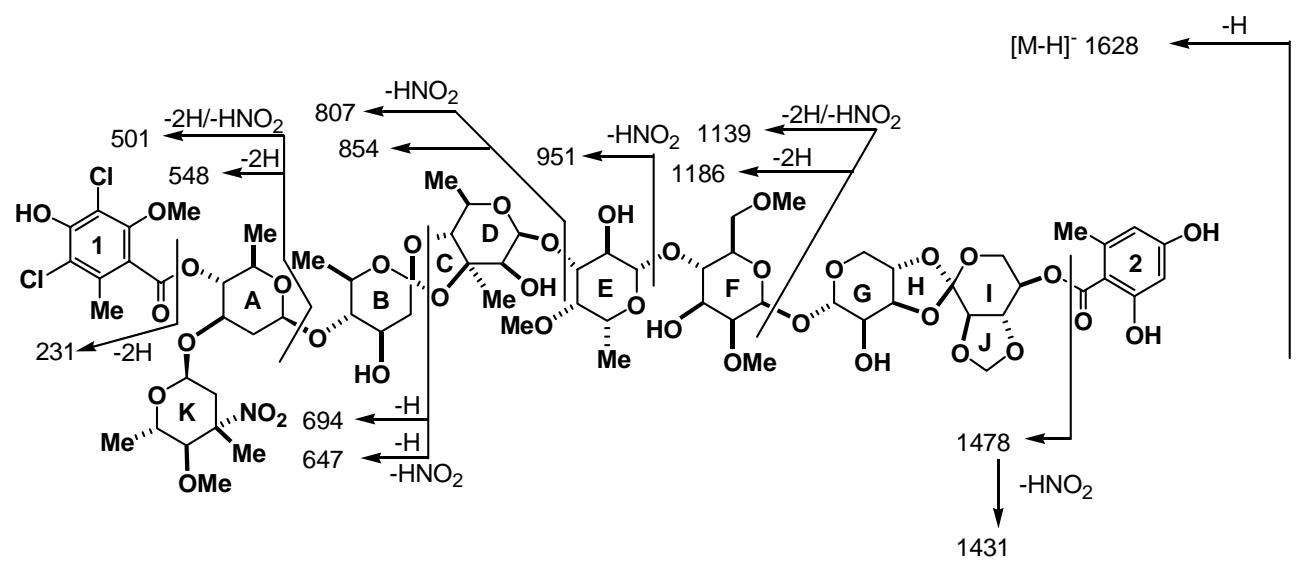

Scheme 2. Proposed negative ion fragmentation pattern of deprotonated SCH 27899 molecule.

In the case of the hydrolysis product of SCH 27899, the fragmentation of negative ions generated much less sequence-specific ions under similar activation conditions (Scheme 3). The conversion of the ortho ester to an ester group drastically alters the fragmentation pattern. For example, the fragmentation pattern of ions at $m / z 1496$ (derived from $m / z \quad 1646 \rightarrow m / z 1496$, Figure 4) from the hydrolysis product is quite different from that of the corresponding ions at $\mathrm{m} / \mathrm{z}$ 1478 (derived from $m / z 1628 \rightarrow m / z$ 1478, Figure 3B) from SCH 27899. The base peak in Figure 4 is at $m / z$ 694, whereas the base peak in Figure 3B is at $m / z$ 1431. A simple bond cleavage of the ester in the hydrolysis site is much more favored than the cleavage of the central ortho ester group in SCH 27899. 


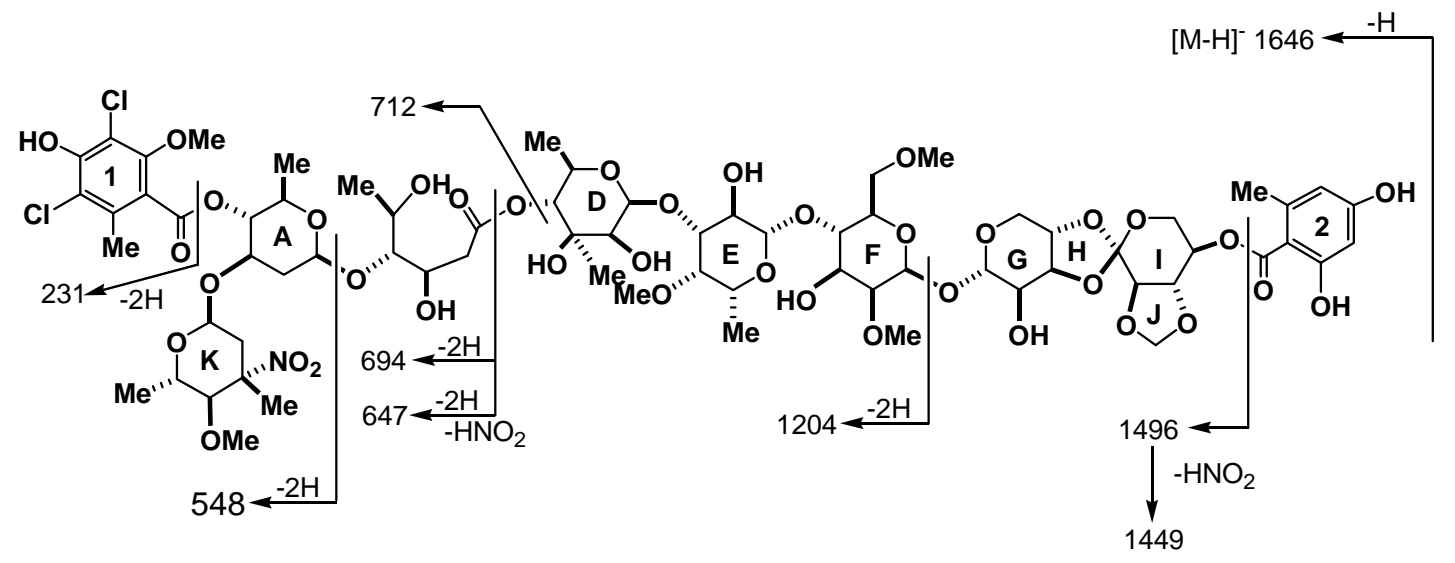

Scheme 3. Proposed negative ion fragmentation pattern of deprotonated SCH 27899 hydrolysis product.

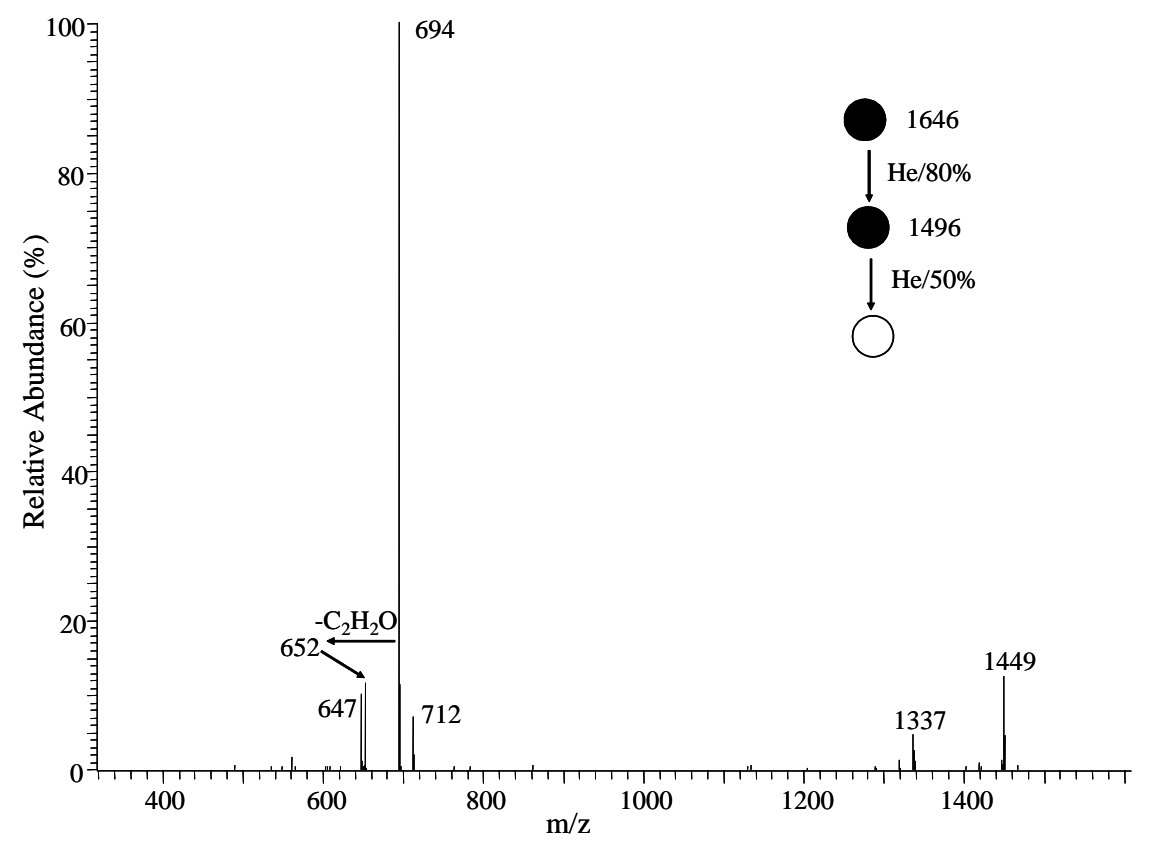

Figure 4. The negative product-ion spectrum $\left(\mathrm{MS}^{3}\right)$ of ion at $\mathrm{m} / \mathrm{z} 1496$ derived from ion at $\mathrm{m} / \mathrm{z}$ $1646\left(\left[\mathrm{M}+\mathrm{H}_{2} \mathrm{O}-\mathrm{H}^{-}\right]^{-}\right)$from SCH 27899 hydrolysis product.

As in the case of everninomicin-D, the negative charge is most likely to be retained in ring 1 with deprotonation taking place on the acidic $-\mathrm{OH}$ group. Similar process is taking place in the case of its hydrolyzed molecule. It is interesting to note that deprotonation does not occur at any of the phenolic groups on aromatic ester ring $\underline{2}$ presumably because the phenolic group in ring $\underline{1}$ is more acidic. 
Amino Everninomicin (SCH 27900)

Amino everninomicin is a minor component isolated from the fermentation broth. ${ }^{31}$ Compared with other everninomicins such as everninomicin-D and SCH 27899, SCH 27900 has an amino group on sugar $\mathrm{K}$ instead of a nitro function (Scheme 4). The negative ion ESI-MS analysis of amino everninomicin generated an abundant deprotonated molecule $[\mathrm{M}-\mathrm{H}]^{-}$at $\mathrm{m} / \mathrm{z}$ 1598 with little fragmentation (data not shown).

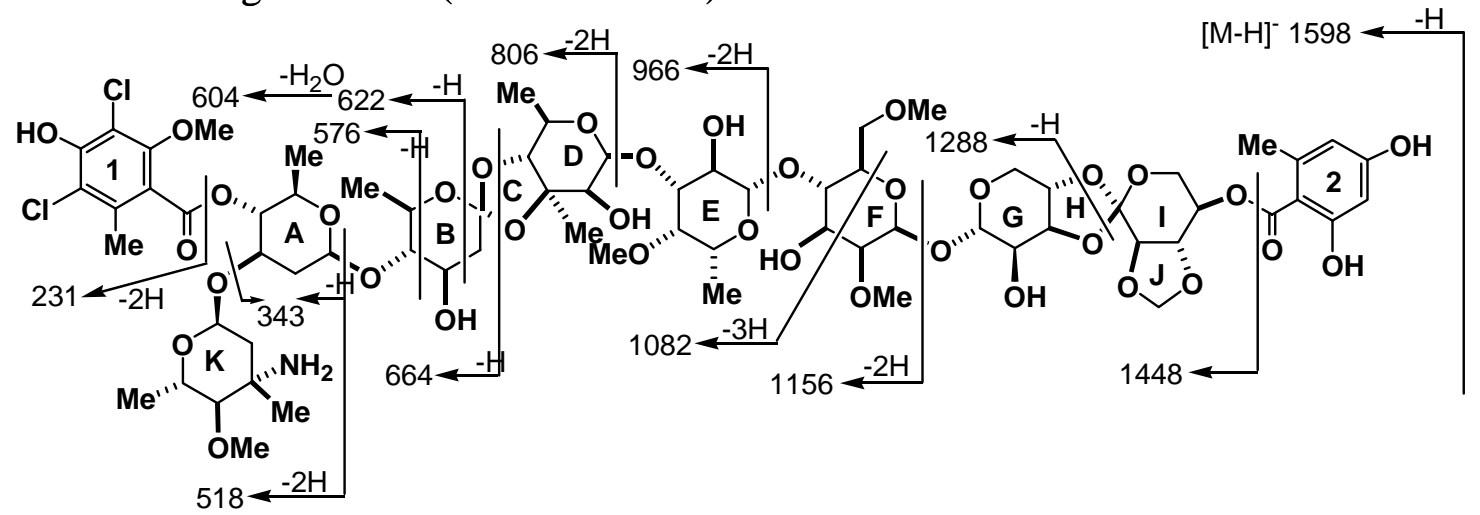

Scheme 4. Proposed negative ion fragmentation pattern of deprotonated amino everninomicin molecule.
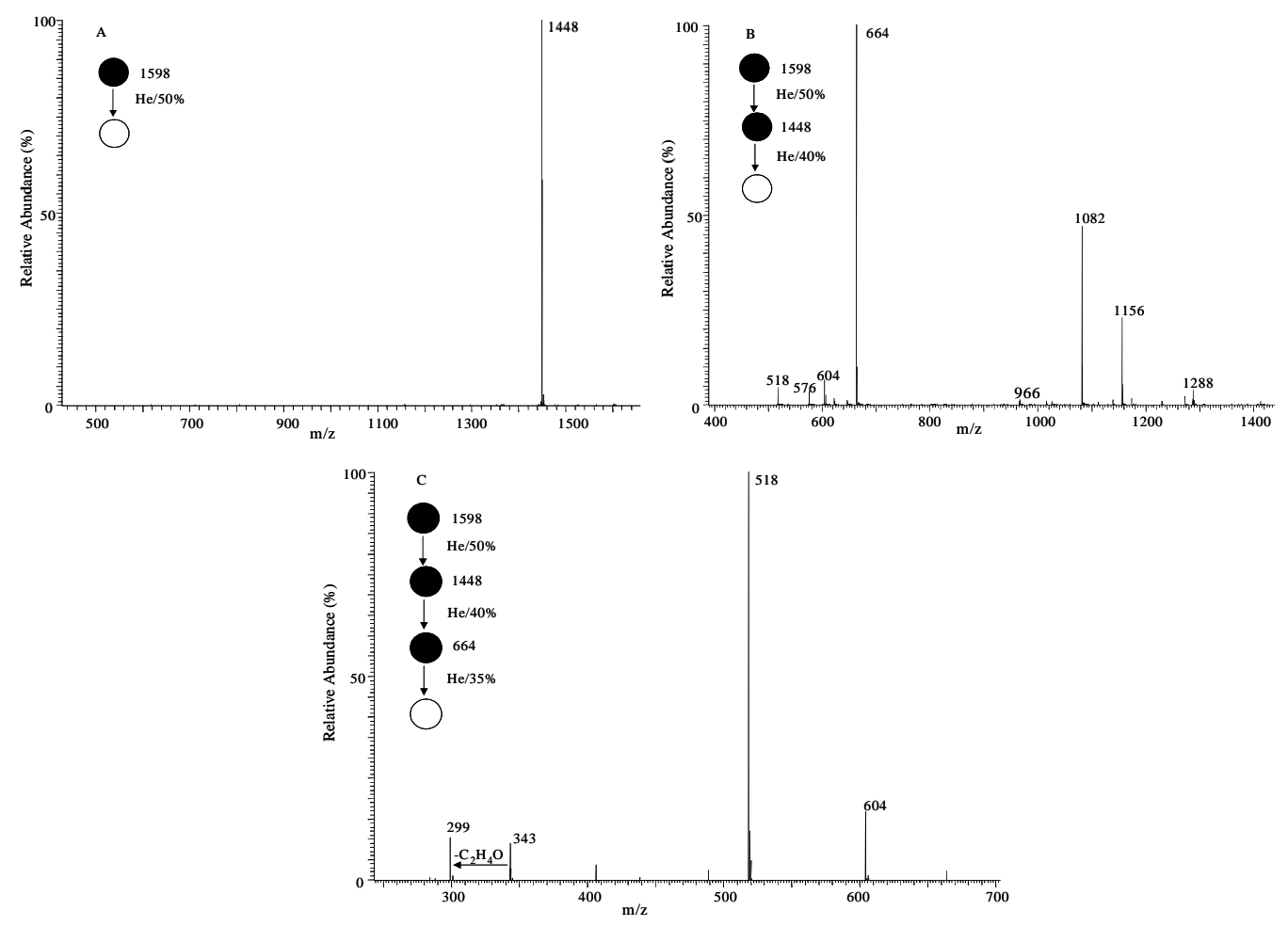

Figure 5. A. The negative product-ion spectrum of ion at $\mathrm{m} / \mathrm{z} 1598\left([\mathrm{M}-\mathrm{H}]^{-}\right)$from amino everninomicin. B. The negative product-ion spectrum $\left(\mathrm{MS}^{3}\right)$ of ion at $\mathrm{m} / \mathrm{z} 1448$ derived from ion at $\mathrm{m} / \mathrm{z}$ 1598. C. The negative product-ion spectrum $\left(\mathrm{MS}^{4}\right)$ of ion at $\mathrm{m} / \mathrm{z} 664$ derived from ion at m/z 1448 . 
The negative ion ESI-MS ${ }^{\mathrm{n}}$ of amino everninomicin gives simple sugar sequence-specific fragment ions (Scheme 4). The deprotonated molecule [M - H] ${ }^{-}$at $m / z 1598$ fragments to yield a product ion at $\mathrm{m} / \mathrm{z} 1448$ as a result of a neutral loss of the aromatic ring $\underline{2}$ (Figure 5A). Several sugar sequence-specific product ions are generated from $\mathrm{m} / \mathrm{z} 1448$ under multiple collision conditions (Figure 5B), i.e. $\mathrm{m} / \mathrm{z} 1288$ (loss of ring 2, I, J and part of ring $\mathrm{H}$ from $\mathrm{m} / \mathrm{z}$ 1448), 1156 (loss of ring $G$ from $m / z$ 1288), 966 (loss of ring $F$ from $m / z$ 1156), and 518 (representing ring 1 , A and K). The most abundant fragment ion is at $m / z 664$ (loss of right portion of the molecule from central ortho ester ring $\mathrm{C}$ ). Collisional activation of this ion produces sugar sequencespecific product ions such as $\mathrm{m} / \mathrm{z} 343$ (Figure 5C, Scheme 4). The negative ion fragmentation pattern for this molecule resembles that of SCH 27899. Both give simple sugar sequence-specific fragmentations. Again, the negative charge is speculated to reside in ring $\underline{1}$ with the deprotonation occurring at the $-\mathrm{OH}$ group. It is important to note that the change of $-\mathrm{NO}_{2}$ group (everninomicin-D and SCH 27899) to amino function (SCH 27900) in ring K eliminates the ready loss of $\mathrm{HNO}_{2}$ during the fragmentation.

\section{SCH 49088}

SCH 49088 is a newly isolated everninomicin antibiotic containing a unique O-alkylated hydroxylamine substituted sugar subunit with carboxyl functionality. ${ }^{32}$ The negative ion ESI-MS spectrum of SCH 49088 exhibits a highly abundant deprotonated molecule [M - H] at $\mathrm{m} / \mathrm{z} 1886$ (data not shown). The ESI-MS ${ }^{\mathrm{n}}$ of this molecule is unique because of the presence of O-alkylated hydroxylamine subunit. A six-stage mass analysis of the deprotonated molecule $[\mathrm{M}-\mathrm{H}]^{-}$at $\mathrm{m} / \mathrm{z}$ 1886 shows the following fragmentation pathway: $\mathrm{m} / \mathrm{z} 1886 \rightarrow \mathrm{m} / \mathrm{z} 1736 \rightarrow \mathrm{m} / \mathrm{z} 1692 \rightarrow \mathrm{m} / \mathrm{z}$ $1463 \rightarrow \mathrm{m} / \mathrm{z} 1319 \rightarrow \mathrm{m} / \mathrm{z} 1273 \rightarrow$ (Figure 6). It is evident from the spectra that most of the fragmentations observed are involved in cleavages of O-alkylated hydroxylamine subunit (ring 3) instead of usual sugar sequence-specific cleavage ions discussed above. The fragmentation patterns are summarized in Scheme 5. For example, the loss of $\mathrm{CO}_{2}$ and ring $\underline{2}$ from the deprotonated molecule leads to the ions at $\mathrm{m} / \mathrm{z} 1842$ and 1736, respectively (Figure 6A). The ions at $\mathrm{m} / \mathrm{z} 1551$ (possible cleavage of ring $\mathrm{K}^{\cdots \cdots} \mathrm{NH}-\mathrm{O}$-ring $\underline{3}$ ) and 1613 (likely cleavage of K-NHO'.ring $\underline{3}_{\text {) }}$ are results of loss of O-alkylated hydroxylamine related subunit (Scheme 5). A further loss of $\mathrm{CO}_{2}$ and O-alkylated hydroxylamine subunit from $\mathrm{m} / \mathrm{z} 1736$ possibly leads to ions at $\mathrm{m} / \mathrm{z} 1692$ and 1463, respectively (Figure 6B). The activation of $\mathrm{m} / \mathrm{z} 1463$ yields the ion of $\mathrm{m} / \mathrm{z}$ 1319, probably through cleavages of ring K (Figure 6D; Scheme 5). Other fragment ions $(\mathrm{m} / \mathrm{z}$ 1273 and 1229) are likely generated by neutral losses of small species $\left(\mathrm{CH}_{2} \mathrm{O}_{2} ; \mathrm{C}_{2} \mathrm{H}_{4} \mathrm{O}\right)$. The fragmentation pattern of SCH 49088 is not unexpected since the deprotonation is more likely to take place at the carboxyl group of the subunit. The negative charge does not appear to be localized during most of the fragmentations. This is in contrast to previous observations of other everninomicins (SCH 27899, everninomicin-D and amino everninomicin) where the negative charge likely resides on the $-\mathrm{OH}$ group of ring 1 , and the sugar sequence-specific fragment ions are generally obtained under similar activation conditions. The introduction of O-alkylated hydroxylamine subunit with the carboxyl group in the molecule significantly changed the negative ion fragmentation pattern, as illustrated in Scheme 5. 


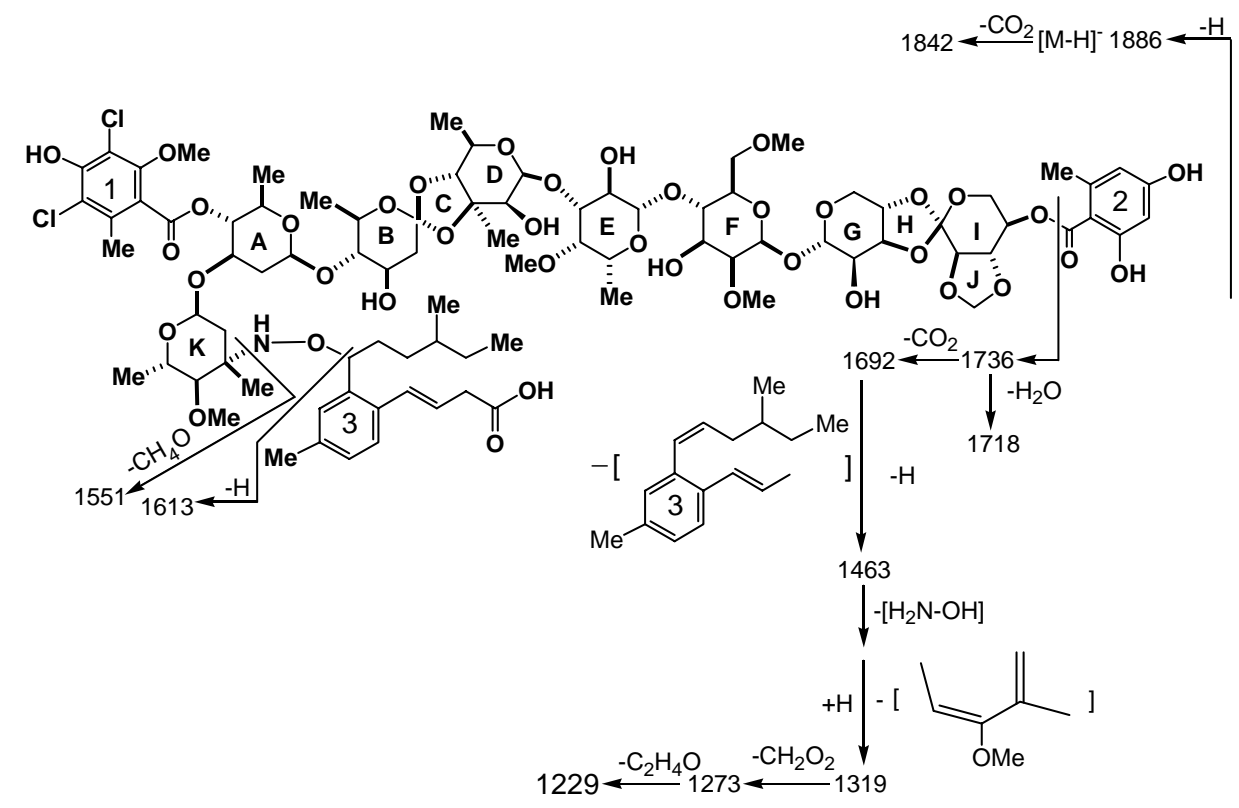

Scheme 5. Proposed negative ion fragmentation pattern of deprotonated SCH 49088 molecule.

\section{Conclusions}

The negative ion ESI-MS has been found to be effective in generating abundant molecular ions for several complex oligosaccharides (everninomicins), including everninomicin-D, SCH 27899, amino everninomicin, and SCH 49088. ESI-MS ${ }^{\mathrm{n}}$ studies of the deprotonated molecules provided detailed structural information involving sugar sequences. This study demonstrated that the negative charge was localized on the more acidic phenolic function of the substituted aromatic ring containing two chlorine atoms. The anionic species appear to undergo fragmentation remote to the charge site. In the case of SCH 49088 that contains a hydroxylamino-ether sugar, much less structurally informative fragment ions were observed. This may because deprotonation is more likely to occur on the carboxyl group of the subunit. Subsequently, it led to a charge-driven process for majority of the fragment ions produced. This strategy of employing negative ion ESI$\mathrm{MS}^{\mathrm{n}}$ to characterize everninomicins can potentially provide a rapid method to probe chemically modified analogues by investigating their detailed fragmentation patterns.
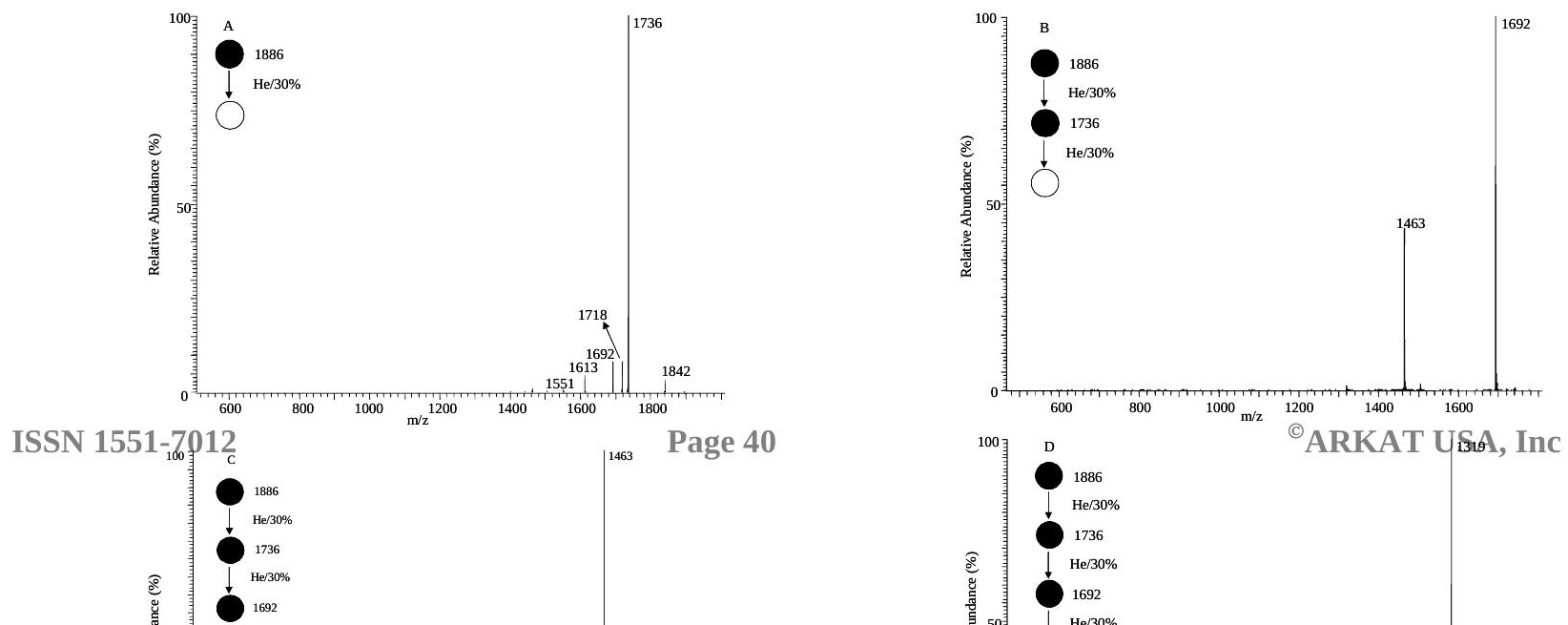
Figure 6. A. The negative product-ion spectrum of ion at $\mathrm{m} / \mathrm{z} 1886\left([\mathrm{M}-\mathrm{H}]^{-}\right)$from SCH 49088. B. The negative product-ion spectrum $\left(\mathrm{MS}^{3}\right)$ of ion at $\mathrm{m} / \mathrm{z} 1736$ derived from ion at $\mathrm{m} / \mathrm{z} 1886$. C. The negative product-ion spectrum $\left(\mathrm{MS}^{4}\right.$ ) of ion at $\mathrm{m} / \mathrm{z} 1692$ derived from ion at $\mathrm{m} / \mathrm{z} 1736$. D. The negative product-ion spectrum $\left(\mathrm{MS}^{5}\right)$ of ion at $\mathrm{m} / \mathrm{z} 1463$ derived from ion at $\mathrm{m} / \mathrm{z} 1692$. E. The negative product-ion spectrum $\left(\mathrm{MS}^{6}\right)$ of ion at $\mathrm{m} / \mathrm{z} 1319$ derived from ion at $\mathrm{m} / \mathrm{z} 1463$. F. The negative product-ion spectrum $\left(\mathrm{MS}^{7}\right)$ of ion at $\mathrm{m} / \mathrm{z} 1273$ derived from ion at $\mathrm{m} / \mathrm{z} 1319$. 


\section{Experimental Section}

General Procedures. Everninomicin-D, SCH 27899, amino everninomicin (SCH 27900), and SCH 49088 were obtained from the fermentation of Micromonospora carbonacea (ScheringPlough Research Institute, Kenilworth, NJ, USA). The procedures were described previously elsewhere. ${ }^{2,11,31,32}$

All experiments were carried out on a Finnigan LCQ-deca (San Jose, CA, USA) ion-trap mass spectrometer equipped with an electrospray ionization source. The sample solution was introduced into the ESI source by direct infusion at a flow rate of $5 \mu \mathrm{l} / \mathrm{min}$. The electrospray needle was held at $4.1 \mathrm{kV}$, and a 20 Psi nitrogen sheath gas was used to stabilize the spray. The heated capillary was set at $250{ }^{\circ} \mathrm{C}$. The helium was introduced into the ion trap to improve the trapping efficiency of the trap including its use as the collision gas during CID. The operational pressure after introducing helium was at $1.4 \times 10^{-5}$ torr.

The instrument was operated in the negative ion mode with the conversion dynode voltage at $15 \mathrm{kV}$. A typical set of experimental parameters included a maximum ion injection time of 250 ms and 3 microscans per analytical scan. In MS ${ }^{\mathrm{n}}$ experiments, the standard resonance excitation was employed. The typical q value was set at 0.25 and activation time at $30 \mathrm{~ms}$ was used. The isolation width was typically at 1.5 Dalton/charge. The activation amplitude, represented as a percentage of full activation voltage, was optimized to facilitate fragmentation of certain ions.

\section{Acknowledgements}

Authors thank Dr. John J. Piwinski for his support to this project.

\section{References}

Presented in part at the $49^{\text {th }}$ American Society for Mass Spectrometry Conference on Mass Spectrometry and Allied Topics, Chicago, Illinois, USA, May 27 - 31, 2001.

1. Weinstein, M. J.; Luedemann, G. M.; Oden, E. M.; Wagman, G. H. Antimicrob. Agents Chemother. 1965, 24, 1964.

2. Girijavallabhan, V. M.; Ganguly, A. K. Kirk-Othmer Encyclopedia of Chemical Technology ( $4^{\text {th }}$ ed.); Wiley: New York, 1992, Vol. 3, p 259.

3. Ganguly, A. K.; McCormick, J. L.; Saksena, A. K.; Das, P. R.; Chan, T.-M. Bioorg. Med. Chem. Lett. 1999, 9, 1209.

4. Foster, D. R.; Rybak, M. J. Pharmacotherapy 1999, 19, 1111.

5. Ganguly, A. K.; Sarre, O. Z.; Greeves, D.; Morton, J. J. Am. Chem. Soc. 1975, 97, 1982.

6. Ganguly, A. K.; Szmulewicz, J. J. Antibiotics 1975, 28, 710.

7. Ganguly, A. K.; Saksena, A. K. J. Antibiotics 1975, 28, 707. 
8. Ganguly, A. K.; Pramanik, B. N.; Girijavallabhan, V. M.; Sarre, O.; Bartner, P. L. J. Antibiotics 1985, 38, 808.

9. Pramanik, B. N.; Ganguly, A. K. Indian J. Chem. 1986, 25B, 1105.

10. Pramanik, B. N.; Das, P. R. J. Natural Products 1989, 52, 534.

11. Ganguly, A. K.; Pramanik, B. N.; Chan, T.-M.; Liu, Y.-H.; Morton, J.; Girijavallabhan, V. M. Heterocycles 1989, 28, 83.

12. Ganguly, A. K.; McCormick, J. L.; Chan, T.-M.; Saksena, A. K.; Das, P. R. Tetrahedron Lett. 1997, 38, 7989.

13. Bartner, P. L.; Pramanik, B. N.; Saksena, A. K.; Liu, Y.-H.; Das, P. R.; Sarre, O.; Ganguly, A. K. J. Am. Soc. Mass Spectrom. 1997, 8, 1134.

14. Pramanik, B. N.; Bartner, P. L.; Chen, G. Current Opinion in Drug Discovery \& Development 1999, 2, 401.

15. Pramanik, B. N.; Shipkova, P. A.; Bartner, P. L.; Heimark, L.; Liu, Y.-H.; Das, P. R.; Saksena, A. K.; Sarre, O. Z.; Girijavallabhan, V. M.; Ganguly, A. K. J. Antibiotics 2000, 53, 640.

16. Shipkova, P. A.; Heimark, L.; Bartner, P. L.; Chen, G.; Pramanik, B. N.; Ganguly, A. K.; Cody, R. B.; Kusai, A. J. Mass Spectrom. 2000, 35, 1252.

17. (a) Fenn, J. B.; Mann, M.; Meng, C. K.; Wong, S. F.; Whitehouse, C. M. Science 1989, 246, 64. (b) Ganguly, A. K.; Pramanik, B. N.; Chen, G.; Shipkova, P. A. "Characterization of Pharmaceuticals and Natural Products by Electrospray Ionization Mass Spectrometry”, 149185, in Applied Electrospray Mass Spectrometry, Pramanik, B. N.; Ganguly, A. K.; Gross, M. L. Eds., Marcel Dekker, Inc., New York, NY, 2002

18. March, R. E.; Hughes, R. J. (Eds.) Quadrupole Storage Mass Spectrometry; Wiley: New York, 1989.

19. March, R. E.; Todd, J. F. J. (Eds.) Practical Aspects of Ion Trap Mass Spectrometry; CRC Press: Boca Raton, FL, 1995.

20. (a) Cooks, R. G.; Chen, G.; Weil, C. Quadrupole Mass Filters and Quadrupole Ion Traps, in Selected Topics in Mass Spectrometry in the Biomolecular Sciences; Caprioli, R. M.; Malorni, A,; Sindona, S. (Eds.); Kluwer Academics Publishers, 1997. (b) Cooks, R. G.; Chen, G.; Wong, P.; Wollnik, H. Mass Spectrometers, in Encyclopedia of Applied Physics, Vol. 19, 289-330, Trigg, G. L. Ed., VCH Publishers, 1997

21. Lin, T.; Glish, G. L. Anal. Chem. 1998, 70, 5162.

22. Ngoka, L. C. M.; Gross, M. L. J. Mass Spectrom. 2000, 35, 265.

23. Shen, J. ; Brodbelt, J. S. Rapid Commun. Mass Spectrom .1999, 13, 1381.

24. Gaucher, S. P.; Leary, J. A. J. Am. Soc. Mass Spectrom. 1999, 10, 269.

25. McLuckey, S. A.; Stephenson, J. L. Mass Spectrom. Rev. 1998, 17, 369.

26. Chen, G.; Pramanik, B. N.; Bartner, P. L.; Saksena, A. K.; Gross, M. L. J. Am. Soc. Mass Spectrom. 2002, 13, 1313.

27. Tomer, K. B.; Crow, F. W.; Gross, M. L. J. Am. Chem. Soc. 1983, 105, 5487.

28. Jensen, N. J.; Tomer, K. B.; Gross, M. L. J. Am. Chem. Soc. 1985, 107, 1863.

29. Adams, J. Mass Spectrom. Rev. 1990, 9, 141.

30. Gross, M. L. Int. J. Mass Spectrom. Ion Proc. 1992, 118/119, 137. 
31. Ganguly, A. K.; Girijavallabhan, V. M.; Miller, G. H.; Sarre, O. Z. J. Antibiotics 1982, 35, 561.

32. Saksena, A. K.; Jao, E.; Murphy, B.; Schumacher, D.; Chan, T.-M.; Puar, M. S.; Jenkins, J. K.; Maloney, D.; Cordero, M.; Pramanik, B. N.; Bartner, P. L.; Das, P. R.; McPhail, A. T.; Girijavallabhan, V. M.; Ganguly, A. K. Tetrahedron Lett. 1998, 39, 8441. 